\title{
Serum Cystatin C as an Early Marker of Neutrophil Gelatinase-associated Lipocalin-positive Acute Kidney Injury Resulting from Cardiopulmonary Bypass in Infants with Congenital Heart Disease
}

\author{
Carrie Herbert, MD, ${ }^{*}$ Mehul Patel, MD, ${ }^{\dagger}$ Alan Nugent, MBBS, ${ }^{*}$ V. Vivian Dimas, MD, ${ }^{*}$ \\ Kristine J. Guleserian, MD, ${ }^{\ddagger}$ Raymond Quigley, MD, ${ }^{*}$ and Vinai Modem, MBBS* \\ *Department of Pediatrics, UT Southwestern Medical Center, Dallas, Tex, USA; 'Department of Pediatrics, University of \\ Michigan Health System, Ann Arbor, Mich, USA; 敋epartment of Cardiothoracic Surgery, Children's Medical Center \\ Dallas, Dallas, Tex, USA
}

\begin{abstract}
A B S T R A C T
Objective. Acute kidney injury (AKI) is a common complication resulting from cardiopulmonary bypass in infants. Urinary neutrophil gelatinase-associated lipocalin (NGAL) is a sensitive and specific marker of such injury. In this study, we compared the performance of serum cystatin C (Cys C) and serum creatinine ( $\mathrm{Cr}$ ) as early markers of renal dysfunction in infants undergoing cardiac surgery under bypass.

Study Design, Setting, and Patients. The study was designed as a prospective observational study. The study was conducted in the cardiac intensive care unit (ICU) of a tertiary, academic children's hospital in the United States. Infants (age $<1$ year) undergoing cardiac surgery under cardiopulmonary bypass were included in the study.

Outcome Measure. Acute kidney injury was defined based on postoperative urinary NGAL.

Results. A total of 17 infants were included in the study, and five of them developed AKI. Serum Cys C and Cr levels were measured postoperatively on days 1,2, and 3, and compared with baseline levels. On postoperative day 2, infants with AKI showed significant change from baseline in serum Cys C levels compared with non-AKI infants ( $28 \%$ vs. $-9 \%, P=.03$ ). The two groups did not show significant differences with respect to rise in serum $\mathrm{Cr}$ on any of the 3 postoperative days. Serum Cr on days 1 and 2 showed nonspecific increases in both AKI and non-AKI groups. The area under the receiver operating characteristic curve for day 2 Cys $\mathrm{C}$ was 0.87 (95\% CI 0.67-1.00) in recognizing NGAL-positive AKI.
\end{abstract}

Conclusions. Postoperative serum Cys $\mathrm{C}$ appears to be a more specific and sensitive biomarker for NGAL-positive AKI resulting from cardiopulmonary bypass surgery in infants undergoing cardiac surgery.

Key Words. AKI; Cardiopulmonary Bypass; Infants; Cystatin C; Creatinine; Urine NGAL

\section{Introduction}

cute kidney injury (AKI) is a well-recognized

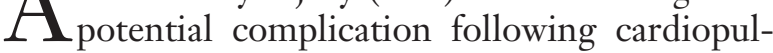
monary bypass $(\mathrm{CPB})$ and circulatory arrest in children undergoing surgery for congenital heart

Grants and funding

This study was funded by the Caruth Center for Pediatric Translational Clinical Research, Children's Health, Dallas, TX. disease (CHD). ${ }^{1}$ It is associated with an increase in in-hospital mortality, longer mechanical ventilation times, and longer duration of inotropic support in these children. ${ }^{2,3}$ Hence, early identification of AKI is essential in these patients. Serum creatinine $(\mathrm{Cr})$ is the conventional biomarker that is commonly used to identify such AKI. But $\mathrm{Cr}$ is a marker of glomerular filtration rate (GFR) rather than injury to the kidney itself. Serum concentration does not increase significantly until approximately $50 \%$ of renal function is lost. ${ }^{4}$ As a result, 
there is a time lag between initiation of AKI and rise in serum $\mathrm{Cr}$ that can result in delayed identification. Also, if early rise in serum $\mathrm{Cr}$ does occur, it is nonspecific and can simply reflect prerenal state. Hence, it has various limitations in being a good marker for renal function in AKI.

Cystatin C (Cys C) is a cationic nonglycosylated low-molecular-weight inhibitor of cysteine proteases that is produced by all nucleated cells. It was first proposed as a marker for GFR in 1985. ${ }^{5,6}$ There is increasing evidence that serum Cys $\mathrm{C}$ can be used as an early biomarker of AKI resulting from CPB. ${ }^{7,8}$ Multiple studies have evaluated its performance in comparison with serum $\mathrm{Cr}^{7-11} \mathrm{~A}$ potential limitation of these studies is that they define AKI based on increase in serum $\mathrm{Cr}$ or decrease in Cr-based GFR measurements. Recent evidence suggests that urinary neutrophil gelatinase-associated lipocalin (NGAL) is a more specific and sensitive early marker of AKI in this patient population. ${ }^{12,13}$ The purpose of this study was to evaluate serum Cys $\mathrm{C}$ as an early biomarker of renal dysfunction in patients with NGALpositive AKI sustained during $\mathrm{CPB}$, defining AKI based on urinary NGAL instead of serum Cr. As a secondary objective, we also evaluated the utility of $\mathrm{Cr}$ clearance measurement based on an abbreviated 4-hour urine collection in this setting.

\section{Methods}

This study was performed at the cardiac intensive care unit (ICU) in Children's Medical Center Dallas (CMCD) over a 1-year period from July 2011 through June 2012. It was designed as a prospective observational cohort study and was approved by the local Institutional Review Board. We compared children with and without AKI, with respect to serum Cys $\mathrm{C}$ and serum Cr. AKI was defined as post-CPB urinary NGAL > $150 \mathrm{ng} /$ $\mathrm{mL}$. The study was limited to term infants under 12 months of age as this is the age group with the highest incidence of AKI secondary to CPB. Children undergoing cardiac surgery under $\mathrm{CPB}$ support were enrolled in the study after obtaining informed consent and Health Insurance Portability and Accountability Act of 1996 authorization. Those with exposure to nephrotoxic medications and intravenous contrast and/or evidence of AKI prior to CPB, defined as meeting "Risk," "Injury," or "Failure," criteria of pRIFLE during the preceding 3 days before surgery, were excluded to avoid the confounding effect on postoperative serum Cys $\mathrm{C}$ level, serum $\mathrm{Cr}$, and $\mathrm{Cr}$ clearance. ${ }^{14}$
In addition, children with evidence of chronic kidney disease (CKD), based on either the estimated Cr clearance using Schwartz's formula or measured $\mathrm{Cr}$ clearance in a 24-hour urine collection, were excluded to avoid the confounding effect of CKD on postoperative serum Cys C levels, serum $\mathrm{Cr}$, and $\mathrm{Cr}$ clearance. $\mathrm{CKD}$ was defined as estimated GFR less than 2 standard deviations below age-based mean GFR.

Patient demographic data, including age, gender, weight, type of cardiac lesion, anthropometric data, and surgical information, were obtained. Surgical complexity was ranked according to the Risk Adjustment for Congenital Heart Surgery 1 (RACHS-1) scoring system. ${ }^{15}$ Intraoperative data obtained included duration of $\mathrm{CPB}$, cross-clamp time, and circulatory arrest time. Postoperative hourly urine output and need for renal replacement therapy (RRT) were monitored.

Urine and serum samples were obtained prior to surgery to measure the baseline urinary NGAL, serum Cr, and serum Cys C. A fresh urine sample was obtained within 4-6 hours after coming off of $\mathrm{CPB}$ to measure postoperative urinary NGAL. ${ }^{12}$ Serum and urine samples were obtained on postoperative days (POD) 1, 2, and 3 to measure serum Cys $\mathrm{C}$, serum $\mathrm{Cr}$, and 4-hour urine $\mathrm{Cr}$ clearance on those days.

\section{Urine NGAL Measurement}

Two $\mathrm{mL}$ of the urine sample collected for NGAL measurement was sent to the core chemistry lab at CMCD immediately after collection. The sample was centrifuged at $1840 \mathrm{~g}$ for 10 minutes and $1.5 \mathrm{~mL}$ of supernatant was obtained and frozen within 1 hour of collection and stored at $-70^{\circ} \mathrm{C}$. Samples were sent in batches to the Biomarker Laboratory (Cincinnati Children's Research Foundation, Cincinnati, OH) for analysis. They were analyzed by enzyme-linked immunosorbent assay (ELISA) using NGAL Rapid ELISA Kit (Kit 037, Bioporto Diagnostics, Gentofte, Denmark) and reported in $\mathrm{ng} / \mathrm{mL}$. The cutoff used was $150 \mathrm{ng} / \mathrm{mL}$ and AKI was diagnosed if it was $>150 \mathrm{ng} / \mathrm{mL} .^{13}$

\section{Serum Cys C Measurement}

One $\mathrm{mL}$ of blood sample collected for serum Cys $\mathrm{C}$ measurement was sent to the core chemistry lab at CMCD. Serum $(0.5 \mathrm{~mL})$ was obtained from this sample and frozen within 1 hour of collection and stored at $-20^{\circ} \mathrm{C}$. It was then shipped to an outside lab (Mayo Medical Laboratories, Rochester, MN). The sample was analyzed by latex particle- 
enhanced immunonephelometry using BN II System (Dade Behring, Deerfield, IL, USA) and reported in $\mathrm{mg} / \mathrm{L} .{ }^{16}$ Serum Cys C-based GFR was calculated using the formula $\log (\mathrm{GFR})=1.962+$ $(1.123 \times \log [1 / \mathrm{CysC}]) \cdot{ }^{17,18} \mathrm{Cr}$-based GFR was calculated using the Schwartz formula. ${ }^{19,20}$

\section{Statistical Analysis}

The cohort of patients was grouped into AKI and non-AKI groups based on postoperative urinary NGAL measurements. The two groups were compared with respect to baseline characteristics. Serum Cys $\mathrm{C}$ and $\mathrm{Cr}$ between the two groups were compared with respect to change from baseline and estimated GFR on each of PODs 1, 2, and 3. Also, sensitivity and specificity of Cys $\mathrm{C}$ and $\mathrm{Cr}$ in identifying NGAL-positive AKI were calculated. Receiver operating curves were constructed and area under the curves compared. Acute kidney injury and non-AKI groups were also compared with respect to hourly urine output and abbreviated 4-hour Cr clearance on PODs 1, 2, and 3. Twotailed Wilcoxon rank sum tests and paired $t$-tests were used for continuous variables and Fisher's exact tests for categorical variables. All statistical analyses were performed using $\mathrm{R}$ version 3.1.0. ${ }^{21,22}$

\section{Results}

A total of 20 patients were enrolled in the study. Three of the 20 patients were excluded due to absence of postoperative urinary NGAL data. Of the 17 patients included in the final analysis, five developed AKI based on postoperative urinary NGAL $>150 \mathrm{ng} / \mathrm{mL}$. Median age of the cohort was 76 days (range 5, 272 days) and median weight was $3.5 \mathrm{~kg}$ (range 2.5 to $8.9 \mathrm{~kg}$ ). Median surgical complexity ranking based on risk adjustment for congenital heart disease (RACHS-1) was 3 (range 1, 6). There was male preponderance, with 12 males and 5 females in this cohort. Eight patients had lesions with single ventricle physiology. The median CPB time was 108 minutes (range 21, 163 minutes) and the median aortic cross-clamp time was 74 minutes (range 0,103 minutes). Only three patients had circulatory arrest $(3,9$, and 16 minutes), and two of them developed AKI.

Table 1 compares baseline characteristics between AKI and non-AKI groups. Children in the AKI group were younger compared with nonAKI group (median age 5 vs. 99 days, $P=.007$ ). They also had more complex surgeries (median RACHS-1 ranking 4 vs. $2.5, P=.04$ ). AKI group had longer durations of $\mathrm{CPB}$ (130 vs. 84 minutes, $P=.01$ ) and cross-clamp times (92 vs. 66 minutes, $P=.06)$, and required other vasopressor/inotropic support in addition to milrinone. Baseline serum $\mathrm{Cr}$ was higher and Cr-based estimated baseline GFR lower in the AKI group compared with nonAKI group. But baseline Cys C and Cys C-based estimated GFR were similar in the two groups. Baseline urinary NGAL and urine output were within normal limits in both the groups prior to surgery.

The lowest postoperative urinary NGAL was $263 \mathrm{ng} / \mathrm{mL}$ in the AKI group. Postoperative changes in serum Cys $\mathrm{C}$ and $\mathrm{Cr}$ for the two groups are shown in Figure 1. The AKI group did not show statistically significant (at $\alpha=.05$ ) postoperative increase in serum $\mathrm{Cr}$ or decrease in Cr-based GFR compared with baseline on any of the initial 3 PODs (Table 2). Significant postoperative increase

Table 1. Baseline Characteristics-Non-AKI vs. AKI

\begin{tabular}{llcc}
\hline & $\begin{array}{l}\text { Non-AKI Group }(\mathrm{n}=12) \\
\text { Median (Range }\end{array}$ & $\begin{array}{l}\text { AKI Group }(\mathrm{n}=5) \\
\text { Median (Range) }\end{array}$ & $P$ Value* \\
\hline Age (days) & $99(5,272)$ & $5(4,16)$ & .007 \\
Gender-Male:Female (Expressed as Proportion) & $60: 40$ & $75: 25$ & .60 \\
RACHS-1 ranking & $2.5(1,6)$ & $4(3,6)$ & .04 \\
CPB time (minutes) & $84(21,163)$ & $130(115,157)$ & .01 \\
Cross-clamp time (minutes) & $66(0,98)$ & $92(72,103)$ & .06 \\
Baseline Cr (mg/dL) & $0.4(0.3,0.6)$ & $0.6(0.4,0.8)$ & .02 \\
Baseline Cr-based GFR ${ }^{\dagger}\left(\mathrm{mL} / \mathrm{min} / 1.73 \mathrm{~m}^{2}\right)$ & $66(38,93)$ & $36(26,57)$ & .004 \\
Baseline CysC $(\mathrm{mg} / \mathrm{L})$ & $1.2(0.7,1.8)$ & $1.2(1.0,1.8)$ & .79 \\
Baseline CysC-based GFR ${ }^{\ddagger}\left(\mathrm{mL} / \mathrm{min} / 1.73 \mathrm{~m}^{2}\right)$ & $68(48,137)$ & $19(8,92)$ & .96 \\
Baseline NGAL (ng/mL) & $13(2,43)$ & $3.5(1.8,6.6)$ & .68 \\
Baseline hourly urine output $(\mathrm{mL} / \mathrm{kg} / \mathrm{hour})$ & $2.5(1.2,4.3)$ & .54 \\
\hline
\end{tabular}

*Wilcoxon rank-sum test for continuous variables and Fisher's exact test for categorical variables. Bold values indicate statistical significance $P<.05$. †GFR estimated from serum $\mathrm{Cr}$ using Schwartz formula.

FGFR estimated from serum CysC using the formula log $(\mathrm{GFR})=1.962+(1.123 \times \log [1 / \mathrm{CysC}])$.

AKI, acute kidney injury; Cr, creatinine; CPB, cardiopulmonary bypass; Cys C, Cystatin C; GFR, glomerular filtration rate; NGAL, neutrophil gelatinase-associated lipocalin. 


\section{Cystatin C}

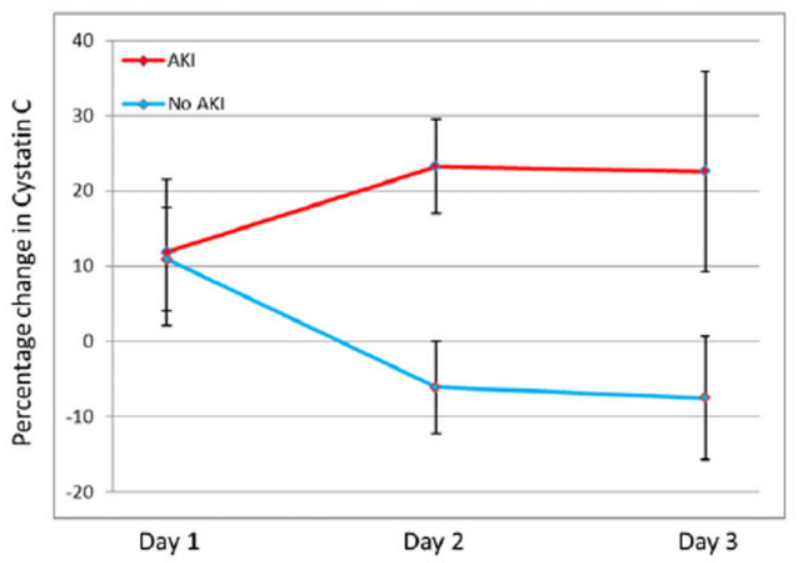

Creatinine

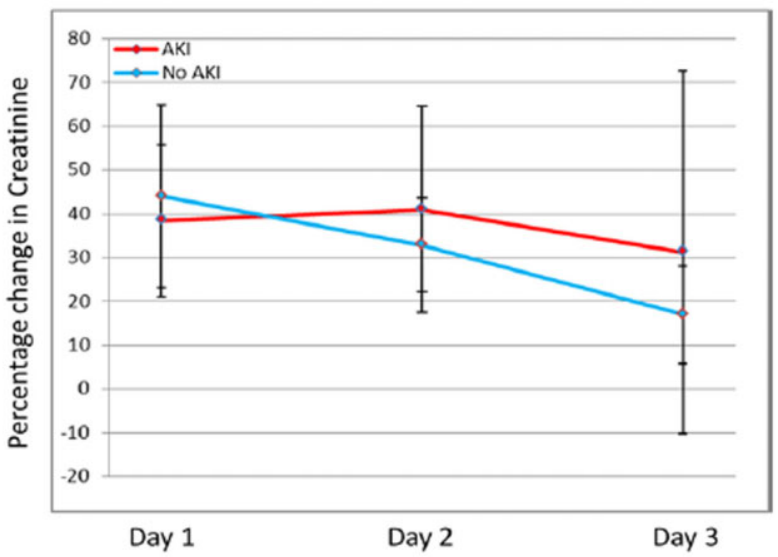

Figure 1. The plot to the left shows percentage change from baseline in Cys $\mathrm{C}$ levels on days 1,2 , and 3 for $\mathrm{AKI}$ and non-AKI groups. The plot on the right shows percentage change from baseline in $\mathrm{Cr}$ levels on days 1,2 , and 3 for $\mathrm{AKI}$ and non-AKI groups. The plotted points represent mean values and the error bars show standard error. AKI, acute kidney injury; Cr, creatinine; Cys C, Cystatin C.

Table 2. Creatinine and Cystatin C-Postoperative Changes from Baseline

\begin{tabular}{|c|c|c|}
\hline & $\begin{array}{l}\text { Non-AKI Group } \\
\text { Mean Difference } \\
(P \text { Value })\end{array}$ & $\begin{array}{l}\text { AKI Group } \\
\text { Mean Difference } \\
\left(P \text { Value }{ }^{\star}\right)\end{array}$ \\
\hline \multicolumn{3}{|l|}{ Increase in $\mathrm{Cr}^{\dagger}$} \\
\hline Postoperative day 1 & $0.15(.04)$ & $0.24(.05)$ \\
\hline Postoperative day 2 & $0.13(.009)$ & $0.28(.15)$ \\
\hline Postoperative day 3 & $0.06(.15)$ & $0.28(.40)$ \\
\hline \multicolumn{3}{|l|}{ Increase in $\mathrm{CysC}^{\ddagger}$} \\
\hline Postoperative day 1 & $0.17(.17)$ & $0.10(.47)$ \\
\hline Postoperative day 2 & $0.06(.44)$ & $0.32(.02)$ \\
\hline Postoperative day 3 & $0.11(.33)$ & $0.40(.20)$ \\
\hline \multicolumn{3}{|l|}{$\begin{array}{l}\text { Decrease in Cr-based } \\
\quad \text { GFR }^{\S},\end{array}$} \\
\hline Postoperative day 1 & $11(.20)$ & $6(.40)$ \\
\hline Postoperative day 2 & $13(.02)$ & $5(.50)$ \\
\hline Postoperative day 3 & $5(.37)$ & $28(.48)$ \\
\hline \multicolumn{3}{|l|}{$\begin{array}{l}\text { Decrease in Cys-based } \\
\text { GFR } \$ \text {, }\end{array}$} \\
\hline Postoperative day 1 & $1(.65)$ & $9(.24)$ \\
\hline Postoperative day 2 & $-11(.04)$ & $14(.04)$ \\
\hline Postoperative day 3 & $-14(.07)$ & $8(.23)$ \\
\hline
\end{tabular}

${ }^{*}$ Paired $t$-test.

${ }^{\dagger} \mathrm{Cr}$ in $\mathrm{mg} / \mathrm{dL}$.

$\ddagger$ CysC in $\mathrm{mg} / \mathrm{L}$.

$\S \mathrm{GFR}$ in $\mathrm{mL} / \mathrm{min} / 1.73 \mathrm{~m} 2$

GFR estimated from serum Cr using Schwartz formula

"GFR estimated from serum CysC using the formula log $($ GFR $)=1.962+(1.123 \times \log [1 /$ CysC $])$.

AKI, acute kidney injury; Cr, creatinine; Cys C, Cystatin C; GFR, glomerular filtration rate. Bold values indicate statistical significance $P<.05$.

in serum Cys $\mathrm{C}$ and decrease in Cys C-based GFR were noted on POD 2 in the AKI group (Table 2). Interestingly, significant postoperative elevation in serum $\mathrm{Cr}$ was noted in the non-AKI group. Serum Cys $\mathrm{C}$ did not show such elevation in this group. The AKI and non-AKI groups differed with respect to serum Cys $\mathrm{C}$ on PODs $2(P=.03)$ and $3(P=.09)$, but not with respect to serum $\operatorname{Cr}(P=.75$ and .71 , respectively) (Figure 2).

Figure 3 shows comparison between non-AKI and AKI groups with respect to urine output and 4-hour abbreviated $\mathrm{Cr}$ clearance. Urine output was a good marker of AKI on POD 1, with all patients in the non-AKI group having a urine output $>1 \mathrm{~mL} / \mathrm{kg} /$ hour and most patients in the AKI group $<1 \mathrm{~mL} / \mathrm{kg} /$ hour $(P=.002)$. But urine output normalizes in the AKI group on PODs 2 and $3(P=.44$ and .72 , respectively). Similarly, abbreviated $\mathrm{Cr}$ clearance based on a 4-hour urine collection showed significant difference between the two groups on POD $1(P=.002)$ and no difference on days 2 and $3(P=.64$ and .54 , respectively).

Performances of Cys C-based and Cr-based estimations of GFR to diagnose AKI were assessed using urinary NGAL as the gold-standard test. Decrease in GFR of $\geq 25 \%$ from baseline was used as the cutoff for both Cr-based estimates and Cys C-based estimates. Cys C showed good specificity on each of the three PODs $(0.78,0.89$, and 0.89 , respectively). But the sensitivity was poor $(0.20$, 0.40 , and 0.50 , respectively). In contrast, $\mathrm{Cr}$ showed poor specificity $(0.58,0.50$, and 0.75 , respectively) but better sensitivity $(0.80,0.60$, and 0.40 , respectively) on each of the three PODs. When the highest decrease in GFR between days 2 and 3 was used, Cys $\mathrm{C}$ performed better compared with $\mathrm{Cr}$ with respect to both sensitivity $(0.80$ vs. 0.60$)$ as well as specificity ( 0.89 vs. 0.50$)$. Positive predictive value was 0.80 for Cys C compared 

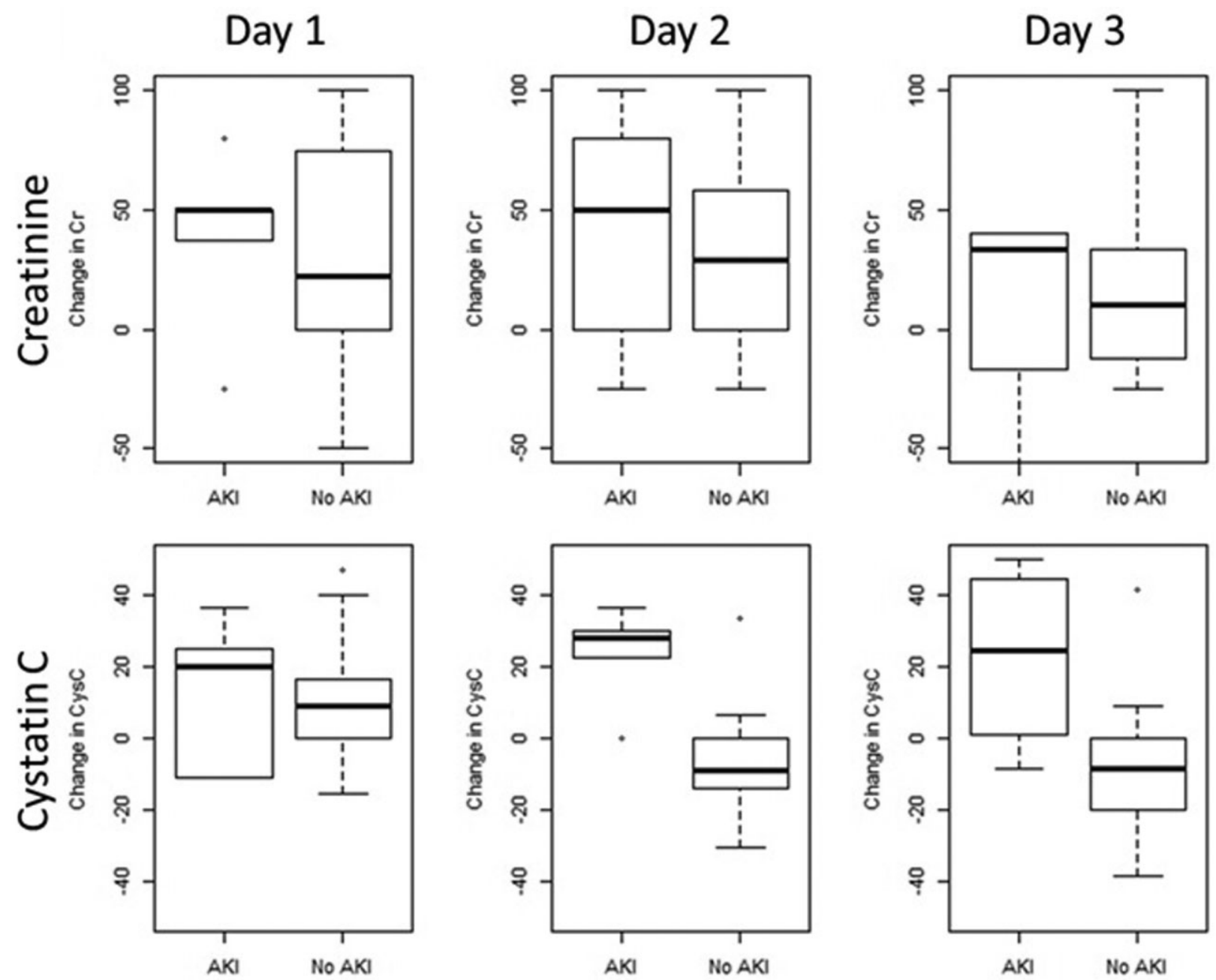

Figure 2. The figure shows box plots comparing infants with and without AKI. Top row compares the change in serum $\mathrm{Cr}$ from baseline and bottom row compares change in serum Cys $\mathrm{C}$ levels from baseline. First column shows changes noted on day 1 , second column shows changes noted on day 2 , and third column shows changed noted on day 3 . AKI, acute kidney injury; Cr, creatinine; Cys C, Cystatin C.

with 0.33 for $\mathrm{Cr}$, and negative predictive value was 0.89 for Cys C compared with 0.75 for Cr. Figure 4 shows receiver operating characteristic curves for Cys $\mathrm{C}$ and $\mathrm{Cr}$ for PODs 1, 2, and 3. The areas under the curve for day 2 were 0.87 and 0.58 , respectively, for Cys $\mathrm{C}$ and $\mathrm{Cr}$. A cutoff value of about $15 \%$ increase from baseline for Cys $\mathrm{C}$ on POD 2 provided the best sensitivity and specificity (0.80 and 0.89 , respectively).

\section{Discussion}

In the recent literature, serum Cys $\mathrm{C}$ has shown promise as a potential early biomarker of AKI and measure of GFR in children sustaining AKI due to CPB. In this study, we compared Cys $\mathrm{C}$ with $\mathrm{Cr}$ in recognizing NGAL-positive AKI. We found that
Cys $\mathrm{C}$ is a more specific marker of AKI compared with Cr. Cys C levels on POD 2 had the best discriminatory ability with an area under the receiver operating characteristic curve of 0.87 . In contrast, there was significant elevation of $\mathrm{Cr}$ in most patients after CPB, irrespective of whether they developed AKI or not, and poor correlation with severity of AKI as measured by post-CPB urinary NGAL levels.

In our cohort, we noticed a significant difference in baseline $\mathrm{Cr}$ as well as Cr-based estimates of GFR between the AKI and non-AKI groups. AKI group had higher $\mathrm{Cr}$ at baseline (preoperatively) even though there was no evidence of AKI at that time as evidenced by normal preoperative urinary NGAL levels. This is likely reflective of the age difference between the two groups. Because all the children 
Day 1
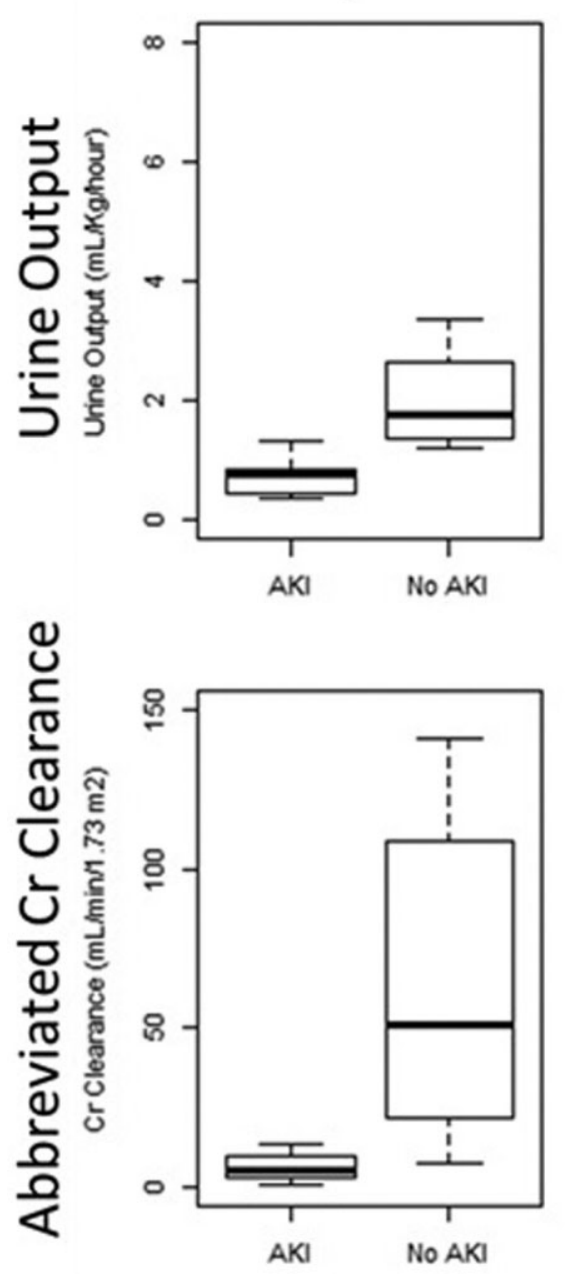

Day 2
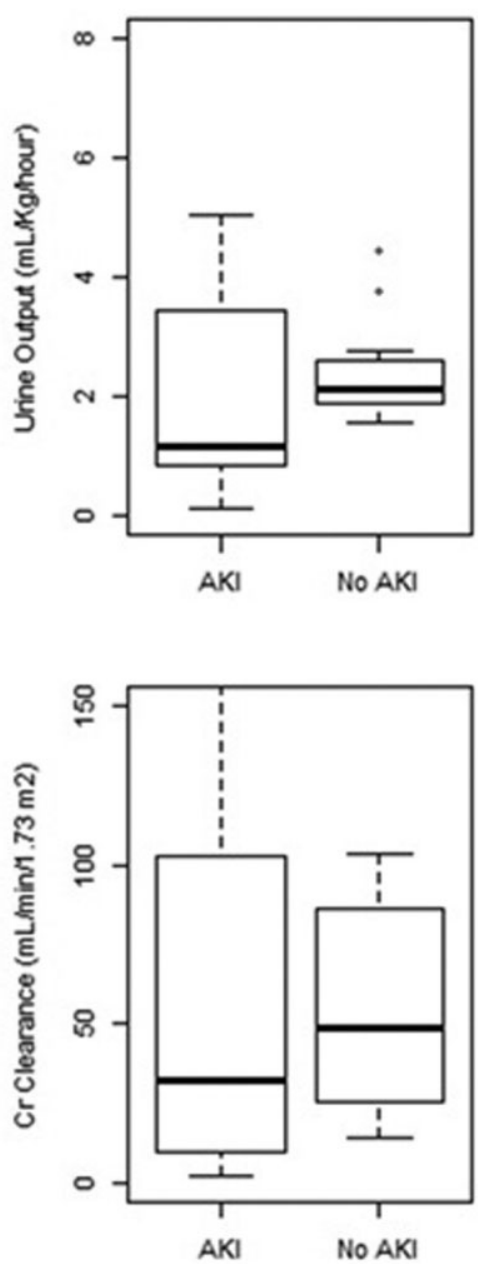

Day 3
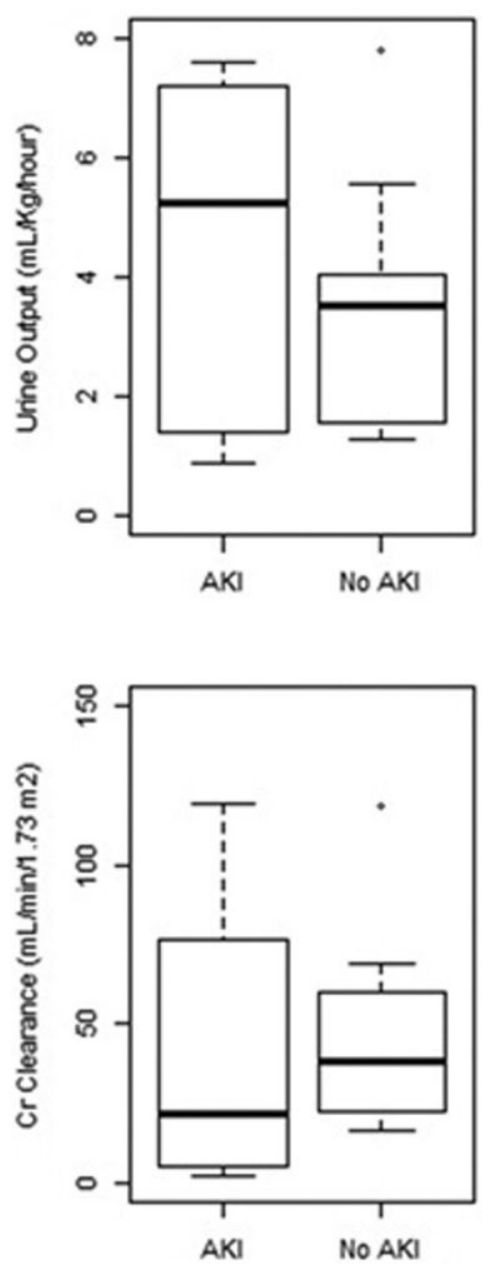

Figure 3. The figure shows boxplots comparing infants with and without AKI. Top row compares the hourly urine output and bottom row compares measured Cr clearance based on a 4-hour abbreviated urine collection. First column shows changes noted on day 1 , second column shows changes noted on day 2 , and third column shows changed noted on day 3 . AKI, acute kidney injury; Cr, creatinine.

with AKI were neonates, their serum Cr levels were higher. Serum Cys C did not show such difference between the two groups at baseline, prior to going on CPB. Presumably this is indicative of the fact that Cys $\mathrm{C}$ is a more reliable marker of AKI, especially in the neonatal age group.

Serum $\mathrm{Cr}$ showed a postoperative rise in both $\mathrm{AKI}$ and non-AKI groups, with a mean increase of around $40 \%$ from baseline on day 1 and of about $30-40 \%$ on day 2 in both groups. The reason for this nonspecific rise is unclear but may be reflective of prerenal state associated with $\mathrm{CPB}$ rather than true AKI. This further supports the fact that serum $\mathrm{Cr}$ has poor specificity in identifying true AKI, especially during the early stages. Serum Cys $\mathrm{C}$, on the other hand, did not show any significant rise postoperatively in the non-AKI group, on any of the 3 days. But, in the AKI group, there was significant rise on POD 2. We failed to notice a difference in Cys $\mathrm{C}$ levels in the AKI group on POD 1, despite previous studies showing a rise in Cys $\mathrm{C}$ levels in AKI patients as early as 8-12 hours postinjury. The dilutional effect of $\mathrm{CPB}$ could potentially explain this observation in our cohort. Similarly, we failed to notice a difference in Cys C levels on POD 3. This is likely suggestive of improvement in renal function, with a return of the Cys C levels back toward baseline on day 3 . Of the five patients with AKI, only one had significant renal dysfunction requiring RRT. This patient's severe AKI was identified by a very high urinary NGAL post-CPB (>1500 ng/mL). Also, 

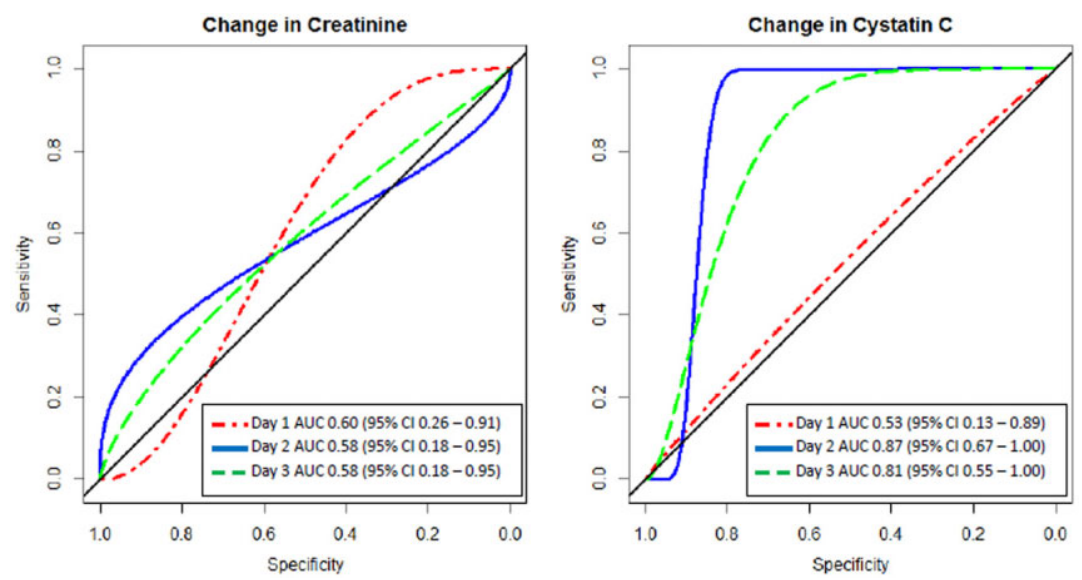

Figure 4. The figure on the left shows receiver operating characteristic curves for serum Cr on days 1, 2, and 3 to identify NGAL-positive AKI. The figure on the right shows receiver operating characteristic curves for serum Cys $\mathrm{C}$. Areas under the curves with $95 \%$ confidence intervals for each of them are shown in the inset boxes.

his serum Cys C was $2.2 \mathrm{mg} / \mathrm{L}$ on POD 2 and continued to rise to $2.7 \mathrm{mg} / \mathrm{L}$ on POD 3. Serum $\mathrm{Cr}$ also showed progressive worsening from days 1 to 3 in this patient. Another patient with more severe AKI (post-CPB NGAL > $500 \mathrm{ng} / \mathrm{mL}$ ) also showed a progressively worsening serum Cys C, peaking at $2.5 \mathrm{mg} / \mathrm{L}$ on day 3 . The other three patients with milder AKI (post-CPB NGAL $<500 \mathrm{ng} / \mathrm{mL}$ ) had short, relatively benign courses in the cardiac ICU.

Previous studies in the recent literature have evaluated serum Cys C as an early marker of AKI, as well as its severity, in children sustaining AKI secondary to $\mathrm{CPB} .^{7-11}$ They have shown that it is a good marker. But all of these studies are limited by the fact that AKI was defined using either serum $\mathrm{Cr}$ or Cr-based estimations of GFR. In this study, we defined AKI based on urinary NGAL levels. The etiology for AKI in postcardiac surgery children can be multifactorial. Urinary NGAL levels at 4-6 hours post-CPB have been shown to detect $\mathrm{AKI}$ resulting from the $\mathrm{CPB}$, with excellent sensitivity and specificity. ${ }^{12}$ As we were specifically interested in identifying $\mathrm{AKI}$ resulting from $\mathrm{CPB}$ and no other etiologies, using urinary NGAL instead of serum Cr helped us in making a more rational comparison between Cys $\mathrm{C}$ and $\mathrm{Cr}$ in identifying such injury. Another major limitation of the previous studies is the wide age range of the cohorts. Serum Cys C levels are higher in the infants, especially during the neonatal period. ${ }^{23}$ But this is the age group at higher risk for developing AKI. Hence, the higher Cys C levels seen in the AKI groups in previous studies may simply reflect the fact that the AKI group had younger children compared with the non-AKI group. In our study, to overcome this limitation, we restricted the age for inclusion to less than 1 year. Also, we evaluated the change from baseline instead of absolute value of Cys C, thus minimizing the effect of intersubject variability.

In our study, we also found that urine output on POD 1 is a very sensitive and specific marker for AKI. But on subsequent days it loses its sensitivity. This could potentially be due to aggressive usage of diuretics during the postoperative period in these infants. Also, abbreviated 4-hour urine collection to measure $\mathrm{Cr}$ collection could be a potentially useful way to assess renal function in these children.

One of the major limitations of our study is the small sample size. But in spite of this limitation, we were able to show significant differences between the performances of Cys $\mathrm{C}$ and $\mathrm{Cr}$ in recognizing NGAL-positive AKI. This sample size yielded a power of $75 \%(\beta=.25)$ for the estimation of area under the receiver operating characteristic curve for Cys C on POD 2. Being a single-center study is another potential limitation. But, on the other hand, the effect of institutional bias is limited as all the patients are from a single institution. Also, our results are consistent with previous studies that have shown similar advantages to using serum Cys $\mathrm{C}$ rather than serum $\mathrm{Cr}$.

\section{Conclusions}

In our small cohort of infants undergoing cardiac surgery under $\mathrm{CPB}$, we found that serum Cys $\mathrm{C}$ is an early and specific biomarker for identification 
of NGAL-positive AKI. It showed best performance characteristics as a marker of AKI on POD 2. Serum Cr, on the other hand, is a sensitive, but very nonspecific marker of such AKI. Future studies should focus on looking at the utility of Cys $\mathrm{C}$ in identifying non-CPB AKI in children with critical illness.

\section{Authors Contributions}

Carrie Herbert-Data acquisition and analysis, drafting of the article, and approval of the submitted final version.

Mehul Patel—Data acquisition and analysis, drafting of the article, and approval of the submitted final version.

Alan Nugent-Research design and interpretation, critical revision of the article, and approval of the final version.

Vivian Dimas-Research design and interpretation, critical revision of the article, and approval of the final version.

Kristine J. Guleserian-Data acquisition, critical revision of the article, and approval of the final version.

Raymond Quigley-Research design and interpretation, critical revision of the article, and approval of final version.

Vinai Modem-Research design, data acquisition, analysis and interpretation, drafting of the article and approval.

Corresponding Author: Vinai Modem, MBBS, Department of Pediatrics, UT Southwestern Medical Center, 5323 Harry Hines Boulevard, Dallas, TX 75390, USA. Tel: 214456 7593; Fax: 214456 7594; E-mail: Modini.Vinai@UTSouthwestern.edu

Conflict of interest: None.

Accepted in final form: Fanuary 18, 2015.

\section{References}

1 Ricci Z, Di Nardo M, Iacoella C, Netto R, Picca S, Cogo P. Pediatric RIFLE for acute kidney injury diagnosis and prognosis for children undergoing cardiac surgery: a single-center prospective observational study. Pediatr Cardiol. 2013;34:14041408.

2 Aydin SI, Seiden HS, Blaufox AD, et al. Acute kidney injury after surgery for congenital heart disease. Ann Thorac Surg. 2012;94:1589-1595.

3 Blinder JJ, Goldstein SL, Lee VV, et al. Congenital heart surgery in infants: effects of acute kidney injury on outcomes. 7 Thorac Cardiovasc Surg. 2012;143:368-374.

4 Coca SG, Parikh CR. Urinary biomarkers for acute kidney injury: perspectives on translation. $\mathrm{Clin} 7 \mathrm{Am}$ Soc Nephrol. 2008;3:481-490.
5 Grubb A, Simonsen O, Sturfelt G, Truedsson L, Thysell H. Serum concentration of cystatin C, factor D and beta 2-microglobulin as a measure of glomerular filtration rate. Acta Med Scand. 1985;218: 499-503.

6 Simonsen O, Grubb A, Thysell H. The blood serum concentration of cystatin C (gamma-trace) as a measure of the glomerular filtration rate. Scand $\mathcal{F}$ Clin Lab Invest. 1985;45:97-101.

7 Krawczeski CD, Vandevoorde RG, Kathman T, et al. Serum cystatin $\mathrm{C}$ is an early predictive biomarker of acute kidney injury after pediatric cardiopulmonary bypass. Clin $7 \mathrm{Am}$ Soc Nephrol. 2010;5:1552-1557.

8 Peco-Antic A, Ivanisevic I, Vulicevic I, et al. Biomarkers of acute kidney injury in pediatric cardiac surgery. Clin Biochem. 2013;46:1244-1251.

9 Hassinger AB, Backer CL, Lane JC, Haymond S, Wang D, Wald EL. Predictive power of serum cystatin $\mathrm{C}$ to detect acute kidney injury and pediatricmodified RIFLE class in children undergoing cardiac surgery. Pediatr Crit Care Med. 2012;13:435440.

10 Seitz S, Rauh M, Gloeckler M, Cesnjevar R, Dittrich S, Koch AM. Cystatin C and neutrophil gelatinase-associated lipocalin: biomarkers for acute kidney injury after congenital heart surgery. Swiss Med Wkly. 2013;143:w13744.

11 Vassalos A, Young D, MacArthur K, Pollock J, Lyall F, Danton MH. Cystatin C: influence of perfusion and myocardial injury on early ( $<24$ hours) renal function after pediatric cardiac surgery. Paediatr Anaesth. 2011;21:1185-1191.

12 Krawczeski CD, Goldstein SL, Woo JG, et al. Temporal relationship and predictive value of urinary acute kidney injury biomarkers after pediatric cardiopulmonary bypass. 7 Am Coll Cardiol. 2011;58: 2301-2309.

13 Krawczeski CD, Woo JG, Wang Y, Bennett MR, Ma Q, Devarajan P. Neutrophil gelatinaseassociated lipocalin concentrations predict development of acute kidney injury in neonates and children after cardiopulmonary bypass. 7 Pediatr. 2011;158: 1009-15.e1.

14 Akcan-Arikan A, Zappitelli M, Loftis LL, Washburn KK, Jefferson LS, Goldstein SL. Modified RIFLE criteria in critically ill children with acute kidney injury. Kidney Int. 2007;71:1028-1035.

15 zJenkins KJ, Gauvreau K, Newburger JW, Spray TL, Moller JH, Iezzoni LI. Consensus-based method for risk adjustment for surgery for congenital heart disease. 7 Thorac Cardiovasc Surg. 2002;123:110-118.

16 Finney H, Newman DJ, Gruber W, Merle P, Price CP. Initial evaluation of cystatin $\mathrm{C}$ measurement by particle-enhanced immunonephelometry on the Behring nephelometer systems (BNA, BN II). Clin Chem. 1997;43(6, pt 1):1016-1022. 
17 Filler G, Lepage N. Should the Schwartz formula for estimation of GFR be replaced by cystatin C formula? Pediatr Nephrol. 2003;18:981-985.

18 Zappitelli M, Parvex P, Joseph L, et al. Derivation and validation of cystatin C-based prediction equations for GFR in children. Am 7 Kidney Dis. 2006; 48:221-230.

19 Schwartz GJ, Haycock GB, Edelmann CM Jr, Spitzer A. A simple estimate of glomerular filtration rate in children derived from body length and plasma creatinine. Pediatrics. 1976;58:259-263.

20 Schwartz GJ, Brion LP, Spitzer A. The use of plasma creatinine concentration for estimating glomerular filtration rate in infants, children, and adolescents. Pediatr Clin North Am. 1987;34:571590.

21 R Core Team. R: A Language and Environment for Statistical Computing. Available at: http://www.Rprojectorg/. Accessed May 22, 2014.

22 Robin X, Turck N, Hainard A, et al. pROC: an open-source package for $\mathrm{R}$ and $\mathrm{S}+$ to analyze and compare ROC curves. BMC Bioinformatics. 2011;12:77.

23 Finney H, Newman DJ, Thakkar H, Fell JM, Price CP. Reference ranges for plasma cystatin $\mathrm{C}$ and creatinine measurements in premature infants, neonates, and older children. Arch Dis Child. 2000;82:71-75. 